\title{
Religião como um sistema de autointer- pretação simbólica: os fundamentos da teoria dos símbolos de Paul Tillich"
}

\author{
Fábio Henrique Abreu**
}

\section{RESUMO}

O presente artigo tem por objetivo elucidar os fundamentos da teoria dos símbolos desenvolvida por Paul Tillich. As pressuposições sistemáticas que conformam o conceito de símbolo de Tillich serão abordadas, num primeiro momento, a partir de uma análise da estrutura fundante de sua teoria do sentido. Além disto, será demonstrado que esta teoria do sentido estabelece o contexto da explicação de Tillich de sua teoria do absoluto, isto é, a estrutura teórica geral a partir da qual o conceito de símbolo é elaborado. A partir da elucidação destes dois elementos teóricos e sistemáticos, o conceito de religião, bem como sua posição particular na totalidade das funções transcendentais do espírito, será abordado em sua peculiaridade. A conclusão do presente estudo jaz na demonstração de que é no símbolo religioso, enquanto estrutura de apresentação da síntese a priori entre a forma do sentido e a substância do sentido, que a consciência realiza tanto a diferença quanto a unidade entre o incondicionado e o condicionado.

Palavras-chave: absoluto; símbolo; teoria do sentido e da religião; forma e substância do sentido; síntese a priori; apresentação.

* Este artigo é um resumo revisado e corrigido de um estudo mais amplo, desenvolvido e publicado no âmbito da Sociedade Paul Tillich do Brasil. A referência aqui é ABREU, 2018, p. 365-582. Agradecemos as cautelosas anotações, críticas e sugestões realizadas pelo Prof. Dr. habil. Christian Danz, as quais tornaram possível a sistematização deste texto.

** Doutor em Ciência da Religião pelo Programa de Pós-graduação em Ciência da Religião da Universidade Federal de Juiz de Fora (PPCIR-UFJF). Atualmente desenvolve pesquisa de habilitação pela Evangelisch-Theologische Fakultät, Universität Wien, sob a supervisão do Prof. Dr. habil. Christian Danz. 


\section{Religion as a System of Symbolic Self-Interpretation: The Founda- tions of Paul Tillich's Theory of Symbols}

\section{ABSTRACT}

The following article aims to elucidate the foundations of the theory of symbols developed by Paul Tillich. The systematic presuppositions that shape Tillich's concept of symbol will be approached, at first, from an analysis of the founding structure of his theory of meaning. Furthermore, it will be demonstrated that this theory of meaning establishes the context of Tillich's explanation of his theory of the absolute, that is, the general theoretical framework from which the concept of symbol is articulated. From the elucidation of these two theoretical and systematic elements, the concept of religion, as well as its particular position in the totality of the transcendental functions of the spirit, will be approached in its peculiarity. The conclusion of the present study lies in the demonstration that it is in the religious symbol, as the structure of the presentation of the synthesis a priori between the form of meaning and the substance of meaning, that consciousness realizes both the difference and the unity between the unconditioned and the conditioned.

Keywords: absolute; symbol; theory of meaning and religion; form and substance of meaning; synthesis a priori; presentation.

O símbolo religioso não necessita de qualquer justificação quando seu sentido é compreendido. Isto porque seu sentido é que ele é a linguagem da religião e a única forma em que a religião pode se expressar diretamente. A religião também pode encontrar expressão, de forma indireta e reflexiva, em termos teológicos, filosóficos e artísticos. No entanto, sua autoexpressão direta é o símbolo e o grupo de símbolos, que aqui chamamos de mito. (TILLICH, 1987e, p. 415)'.

A epígrafe que abre o presente estudo demarca uma característica fundamental, embora extraordinariamente ignorada, da teoria da religião de Paul Tillich². A partir da determinação do símbolo como

Todas as traduções de textos em língua estrangeira para o português, salvo quando - e se - houver menção do contrário, são nossas.

2 A única reconstrução propriamente histórico-genética da teoria dos símbolos de Tillich disponível na literatura secundária contemporânea é de autoria de HEINEMANN, 2017. Uma reconstrução precisa do lugar epistêmico e sistemático do símbolo no pensamento de Tillich também pode ser encontrada no estudo de DANZ, 2000b, p. 300-352, o qual fundamentalmente orienta, de forma geral, o texto ora apresentado. 
"a linguagem da religião", Tillich concede ao símbolo uma posição proeminente em sua filosofia do espírito, do sentido e da religião. Desta perspectiva teórica resulta que o tratamento dos símbolos constitui um aspecto decisivo da consciência religiosa em sua autointerpretação reflexiva. Posto de outra forma, a consciência religiosa somente se revela enquanto propriamente religiosa se e somente se for capaz de adentrar um processo de comunicação simbólica que seja distinto das demais funções culturais. Pois, "a religião não é uma função especial da vida espiritual do homem, mas a dimensão de profundidade em todas as suas funções" (TILLICH, 1959, p. 5-6). Neste contexto, a pergunta pela estrutura específica do conceito tillichiano de símbolo se torna inescapável, uma vez que esta estrutura deve ser capaz de nomear a particularidade da religião, em sua distintividade e relacionalidade, frente a outras funções transcendentais do espírito.

O presente estudo elucida, a partir de uma perspectiva estritamente sistemática, os fundamentos da teoria dos símbolos de Tillich. Os pressupostos epistemológicos e sistemáticos que conformam o conceito de símbolo desenvolvido por Tillich serão abordados, num primeiro momento, a partir de um incurso na estrutura fundante de sua teoria do sentido (Sinntheorie). Sobre os alicerces desta teoria encontram-se os fundamentos tanto para a determinação do conceito de religião quanto para a consequente percepção da consciência religiosa enquanto consciência propriamente simbólica. Num segundo momento, demonstrar-se-á que esta teoria do sentido constitui o contexto de explicação da teoria do absoluto - ou, mais precisamente, do incondicionado (Unbedingte) - desenvolvida por Tillich, isto é, a estrutura teórica geral a partir da qual o conceito de símbolo é elaborado. A partir da elucidação destes dois elementos teóricos e sistemáticos, o conceito de religião, bem como sua posição particular no conjunto das demais funções transcendentais do espírito, poderá ser abordado em sua peculiaridade distintiva. A conclusão do presente estudo jaz na demonstração de que é no símbolo religioso, enquanto estrutura de apresentação da síntese entre a forma do sentido e a substância do sentido, que a consciência realiza tanto a diferença quanto a unidade entre o incondicionado e o condicionado. 


\section{A construção triádica da consciência de sentido - ou, sobre a síntese entre a forma do sentido e a substância do sentido}

Com sua teoria do sentido, Tillich pretende suprassumir, fundamentalmente, a contraposição entre os modelos idealista e realista do conhecimento em uma nova síntese metodológica (TILLICH, 1989a, p. 204-206; TILLICH, 1987b, p. 124-133). Como aponta Tillich:

O método crítico-dialético pressupõe a autonomia do espiritual em contraposição a todo aquele-que-é imediatamente dado (allem unmittelbar Seiendes). Neste sentido, ele não precisa representar um idealismo epistemológico; ele não deve supor que o espírito confere leis à natureza. Não obstante, ele certamente não pode admitir que um realismo epistemológico seja verdadeiro. Ele não pode supor que a natureza confere leis ao espírito. Ele deve pressupor que os princípios de sentido aos quais a consciência se submete no ato espiritual são, ao mesmo tempo, os princípios de sentido aos quais o ser está submetido. Ele deve pressupor que o sentido do ser alcança expressão na consciência formada pelo sentido. (TILLICH, 1987b, p. 125).

Nas palavras de Tillich, o método crítico-dialético deve supor tanto que os princípios de sentido aos quais a consciência se submete no ato espiritual são, ao mesmo tempo, princípios de sentido aos quais o ser está submetido quanto que o sentido do ser somente alcança expressão na consciência formada pelo sentido (TILLICH, 1989a, p. 204-205). A partir de uma reflexão crítica de suas performances, os modelos idealista e realista do conhecimento apresentam fragmentariedade e necessidade de complementação na medida em que encontram problemas que não podem ser elucidados com base em seus próprios pressupostos. Para Tillich, assim como o realismo, como uma análise crítica de seus pressupostos epistemológicos demonstra, é incapaz de explicar como a natureza pode conferir leis ao espírito, o idealismo, por sua vez, é incapaz de explicar como uma substância desprovida de forma pode se tornar capaz de aceitar leis. Sob a perspectiva de sua teoria do sentido, ambos os modelos provam ser abstrações do reconhecimento fundamental que substância (Gehalt) e forma (Form) já configuram uma unidade em cada experiência de sentido (TILLICH, 1987b, p. 134). Como corolário de tais considerações tem-se que, para 
Tillich, a experiência de sentido não pode ser adequadamente descrita nem como doação de sentido (Sinngebung), nem como apreensão de sentido (Sinnerfassung), "mas somente como cumprimento de sentido [Sinnerfüllung]” (DANZ, 2000b, p. 308).

$\mathrm{O}$ conceito indica que as coisas permanecem em seu direcionamento à forma incondicionada e que este direcionamento encontra seu cumprimento (Erfüllung) nas criações espirituais. Nem normas ideais, que jazem além do ser, nem uma realidade de sentido formada em contraposição ao espírito são portadoras de sentido. O sentido não é dado, quer de forma real ou ideal, mas ele é intencionado (intendiert), e alcança seu cumprimento no espírito. (TILLICH, 1924, p. 19).

O conceito de cumprimento de sentido encontra sua função epistêmica na medida em que pressupõe que, em cada processo de atualização da consciência de sentido, substância e forma já sempre configuram,

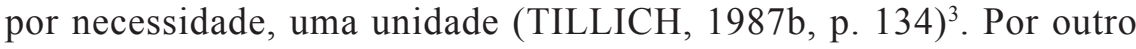
lado, quanto mais o cumprimento de sentido aponta para uma estrutura performática unitária, tanto mais permite designar os momentos que são constitutivos do processo infinito de cumprimento de sentido que caracteriza a vida do espírito (TILICH, 1983, p. 125).

A necessidade de formar conceitos independentes está em todos os lugares em que os elementos de uma realidade unitária provam ser independentemente variáveis. A formação dos conceitos, a emergência de determinados objetos do fluxo absolutamente uniforme da realidade, encontra sua base neste fato. Agora, no entanto, há o fato que, tanto na ontologia quanto na filosofia da história, a forma do sentido e a substância do sentido permanecem, em todas as esferas da realidade, numa relação de tensão uma com a outra, e que nesta tensão jaz a riqueza tanto dos objetos quanto dos processos. Evidentemente, não há elementos isolados. A realidade está sempre em integração. (TILLICH, 1924, p. 19)4.

Como afirma Tillich (1987b, p. 134): „Form und Gehalt gehören zusammen; es ist sinnlos, das eine ohne das andere zu setzen". O estabelecimento de uma diástase entre Form e Gehalt resulta, necessariamente, de toda interpretação ontologizante do pensamento de Tillich. Um típico exemplo, aqui, é o estudo de HERBERGER, 1935, p. 129-141; p. 161175; veja, igualmente, SCHÜßLER, 1986, p. 49-67, que incorre no mesmo equívoco.

4 Nesta conexão, afirma Tillich (1924, p. 19): „Aber es gibt [...] keine vollkommene Integration, keine absolute Synthese. Gäbe es sie, so wäre weder die Dynamik des Geschehens, noch die Möglichkeit der Verunwesung gegeben. Alles Geschehen, alle Lebendigkeit beruht auf der Spannung der Elemente, auf der Variabilität ihrer Relation. Wer darum die Dynamik des Werdens verstehen will, muß diese Elemente in abstracto herausgreifen und ihre Spannungsverhältnisse beobachten“. 
A forma do sentido (Sinnform) e a substância do sentido (Sinngehalt) configuram os momentos estruturais que constituem o processo de cumprimento de sentido, e não quaisquer dados independentemente disponíveis. O relacionamento entre a forma do sentido e a substância do sentido deve ser entendido, consequentemente, como um de estrita interrelação (TILLICH, 1987b, p. 134) . Segue-se que, assim como a forma do sentido jamais pode ser pensada sem a substância, por um lado, também a substância jamais pode ser pensada sem a forma do sentido, por outro (TILLICH, 1987b, p. 134). Caso esta tese de Tillich receba uma leitura mais ampla, deve-se seguramente afirmar, então, que toda forma de percepção é já dotada de sentido, assim como cada percepção de sentido é dependente da mediação através de uma forma. Entre os momentos estruturais do sentido, a saber, a forma de sentido e a substância de sentido, não há somente uma estrita interrelacionalidade contínua, mas uma interrelacionalidade tal que deve ser entendida como independentemente variável. Não se pode operar, portanto, sem o risco de drásticas consequências para a sistematicidade interna do pensamento de Tillich, nem uma identificação entre os conceitos de incondicionado e de substância, por um lado, nem entre os conceitos de condicionado e de forma, por outro ${ }^{6}$.

5 Em função do relacionamento de estrita copertença entre forma e substância, torna-se impossível operar uma identificação entre os conceitos de incondicionado e substância, por um lado, e os conceitos de forma e condicionado, por outro. Tal identificação equívoca pode ser encontrada, por exemplo, na análise do conceito de símbolo de Tillich desenvolvida por Ringleben (1989, p. 165-181, especialmente, p. 166 e 181). Se a interpretação do relacionamento de mútua pertença entre forma e substância operar uma identificação entre o incondicionado e a substância e entre o condicionado e a forma, então seria impossível visualizar como o conceito de símbolo poderia ser defendido frente às objeções críticas, levantadas por Ringleben, que identificam, no pensamento de Tillich, uma diástase entre o incondicionado e o condicionado. O ponto a ser aqui percebido é que as categorias forma e substância constituem, na dinâmica de sua copertença e interrelacionalidade, os meios a partir dos quais o incondicionado encontra expressão. Não há, pois, uma identificação na medida em que o incondicionado se expressa por meio da justaposição de forma e substância. Sobre este ponto, cf. DANZ, 2000b, p. 308-309, nota 17.

6 A questão do relacionamento entre o conceito de incondicionado e a polaridade entre forma e substância ainda constitui um tema de disputa e controvérsia nas pesquisas sobre Tillich. Conjuntamente com interpretações que determinam o incondicionado nos termos de uma descrição do relacionamento entre forma e substância, como o faz, por exemplo, ULRICH, 1971, p. 45, inúmero autores pressupõem uma identificação entre os conceitos de incondicionado e o de substância. Para esta identificação, veja WAGNER, 1973, p. 128, nota 8, que se posiciona contra Thomas Ulrich. Sobre este 
Se o cumprimento de sentido deve ser entendido como unidade entre forma do sentido e substância do sentido, então um momento, que não pode ser deduzido nem da forma do sentido nem da substância do sentido, é também sempre já reivindicado. Este momento é a sintese entre forma e substância, síntese esta já sempre reivindicada no processo de cumprimento de sentido. Tillich tematizou este terceiro momento, que

ponto, cf., igualmente, REPP, 1986, p. 180; p. 238. Na interpretação de SCHÜßLER, 1986, p. 49-67, os termos se tornam, por sua vez, intercambiáveis; outra identificação é operada por Michael Palmer em sua introdução ao segundo volume dos Main Works Hauptwerke de Tillich. Como afirma Palmer (1990, p. 14): “Import', in a word, is the name given to the unconditioned meaning intended in religion and presupposed in every cultural creation". Ainda sobre esta interpretação problemática, veja HAIGIS, 1998, p. 65 ; p. 94. Em que se pesem tais interpretações, no entanto, é preciso notar que, já em 1924, em seu artigo-réplica Zu Tillichs Systematik, Tillich se posiciona contra uma identificação entre o conceito de incondicionado e o conceito de substância. A partir de uma ênfase na interrelação estrita entre forma e substância, Tillich (1924, p. 18) afirma que a identificação entre o incondicionado e a substância implica uma fuga em direção a "uma transcendência vazia [eine leere Transzendenz]". O teor desta ressalva reverbera a crítica de Tillich à teologia de Emanuel Hirsch. Sobre este ponto, cf. TILLICH, 1983, p. 116; p. 118; p. 124. Ainda sobre a identificação problemática entre incondicionado e substância, veja JAHR, 1989, p. 70-85. Em sua interpretação dos escritos tillichianos da década de 20, Jahr $(1989$, p. 82) aponta, em contraposição à própria intenção de Tillich, que há "uma preponderância do significado do elemento da substância em contraposição à forma". Sobre a base do relacionamento estrito entre forma e substância elaborado por Tillich, entretanto, não é possível identificar o que Tillich chama de substância com o incondicionado e o condicionado com a forma. Sobre este ponto, veja TILLICH, 1971, p. 185: „Das Unbedingte des Gehaltes und das Unbedingte der Form gehören wesenhaft zusammen“. Antes, como afirma Danz (2000b, p. 308, nota 17), "substância e forma são simplesmente a expressão do incondicionado, sem que, com isso, o incondicionado coincida com a polaridade". Caso decida-se insistir nesta leitura da relação do conceito de incondicionado com a polaridade de substância e forma enquanto sistematicamente mais fundamental, então também a leitura daquelas passagens em que Tillich opera uma identificação equívoca entre os conceitos de incondicionado e o de substância resultaria em uma interpretação contrária aos interesses do próprio Tillich. Esta identificação, de fato, ocorre, ainda que de modo isolado. Sobre este ponto, veja TILLICH, 1989a, p. 208; TILLICH, 1990b, p. 97. Em que se pesem estas contradições, os equívocos de Tillich encontram-se no processo de elaboração da teoria, e não no sistema teórico tomado em si mesmo. Uma identificação do incondicionado com a substância e do condicionado com a forma conduz a consequências imensuráveis para o conceito de símbolo e, neste sentido, portanto, para a totalidade do pensamento de Tillich. É precisamente este tipo de interpretação que, partindo da identificação do incondicionado com a substância e do condicionado com a forma, resulta numa desconstrução completa de sua teoria dos símbolos. Sobre este ponto, cf. RINGLEBEN, 1989, p. 165-181, aqui, sobretudo, p. 166 e p. 181. Sobre a base desta identificação, o conceito de símbolo ensejaria uma diástase abstrata entre o sentido incondicionado e as formas condicionadas - tal como Ringleben acusa em Tillich - em vez de uma mediação, como Tillich, de fato e de direito, intenciona. 
se encontra sempre e invariavelmente operante em cada experiência de sentido, em diferentes estudos elaborados na década de vinte do século passado. Em seu Wissenschaftssystem e em sua Religionsphilosophie, Tillich dedica tanto o conceito de sentido quanto o conceito de espírito à determinação da síntese entre forma e substância (TILLICH, 1989a, p. 214; TILLICH, 1987b, p. 126). "A duplicidade de forma de sentido e substância de sentido é elementar para cada função de sentido. Esta duplicidade não é nenhum princípio de sentido, mas o próprio princípio do sentido" (TILLICH, 1989a, p. 214). Em seu artigo Kairos und Logos. Eine Untersuchung zur Metaphysik der Erkenntnis, de 1926, Tillich descreve este terceiro momento por meio dos termos "interpretação da essência", "entendimento espiritual da realidade", ou ainda, "decisão" (TILLICH, 1989b, p. 279)7. Em aberta oposição a teorias realistas e idealistas do conhecimento, Tillich afirma "metalogicamente": "uma tal doutrina do conhecimento negligencia, no entanto, um terceiro elemento da cognição que não é nem formal nem material, e que torna a cognição, desta forma, um assunto primariamente espiritual” (TILLICH, 1989b, p. 279).

O conceito de sentido é, assim, erigido por Tillich através de uma estrutura que não pode mais ser adequadamente descrita por meio de uma relação que se quer binária, tal como o esquema sujeito-objeto. Isto porque foi precisamente este modelo cognitivo binário que provocou, de acordo com Tillich, a alternativa entre idealismo e realismo (TILLICH, 1989a, p. 215-217; TILLICH, 1987b, p. 125). Uma superação desta alternativa, tal como Tillich a reivindica com o desenvolvimento de sua teoria do sentido, não pode mais operar dentro dos limites de relações binárias, mas deve se mover, por força de sua própria intenção sistemática, em direção ao estabelecimento "de relações triádicas" (DANZ, 2000b, p. 310). De outra forma, a reivindicação de Tillich de oferecer uma superação da alternativa teórico-cognitiva imposta pelos

7 Neste mesmo contexto, Tillich explica o terceiro elemento, isto é, o momento da síntese entre forma e substância, nos seguintes termos: „Es handelt sich nicht um die Anwendung der Form auf das Material, des Evidenten auf das Wahrscheinliche, also um die ,Urteilskraft'. Sie kann bis zur Genialität geisteigert sein, aber sie hört darum nicht auf, eine technische Funktion zu sein, die der Entscheidung in unserem Sinne entzogen ist. Das dritte Element, von dem wir reden, ist die Wesensdeutung, das geistige Verstehen der Wirklichkeit“". (TILLICH, 1989b, p. 279). 
limites do idealismo e do realismo permaneceria não mais que uma mera promessa. Assim, a síntese entre forma e substância sistematiza, enquanto momento sempre já reivindicado no processo de cumprimento de sentido, o modo como a unidade entre a forma do sentido e a substância do sentido é alcançada pelo espírito. Pois, na medida em que não pode ser deduzida nem da forma do sentido nem da substância do sentido, a síntese constitui um momento terceiro que torna o processo de cognição, conforme afirma Tillich, "um assunto primariamente espiritual” (TILLICH, 1989b, p. 279). Isto implica afirmar que Tillich assume, com sua teoria do sentido, a tarefa sistemática de percorrer o caminho espiritual que parte de uma relação binária em direção a uma relação triádica. Não obstante, assim como o modo de interrelação entre a forma do sentido e a substância do sentido não pode ser reduzido unilateralmente à forma ou à substância, tampouco pode a síntese, através da qual a forma do sentido e a substância do sentido constituem a experiência particular do sentido, ser reduzida a um dos polos desta relação (TILLICH, 1987b, p. 134).

O conceito de símbolo esboçado por Tillich, que se constrói, conforme visto, através da tríade forma, substância e síntese, torna evidente o motivo pelo qual o conceito de sentido somente pode ser pensado nos termos de um encadeamento de sentido, ou melhor, como "um conceito sequencial" (DANZ, 2000b, p. 310).

O sentido individual, que se torna experienciado e atualizado (der erfahren und vollzogen wird), permanece sempre em relação com outros sentidos; à parte destes, o sentido individual seria um frívolo aforisma. Sentido é sempre interconexão de sentido. A quintessência de todas as estruturas de interconexão de sentido é o que denominamos, de forma objetiva, mundo, e, de forma subjetiva, cultura. (TILLICH, 1990c, p. 103) ${ }^{8}$.

De acordo com a citação acima, uma determinada experiência somente pode ser caracterizada como significativa se e somente se permanecer em uma relação de encadeamento sequencial e de interconexão com outras experiências de sentido. É precisamente através do avanço em direção a um contexto sequencial de sentido que uma experiência

Cf., igualmente, TILLICH, 1989a, p. 205; TILLICH, 1987b, p. 133-157. 
pode ser qualificada como dotada de sentido, na medida em que esta experiência passa a ocupar uma posição determinada na estrutura de interconexão de sentido, tornando-se, assim, determinada, ao mesmo

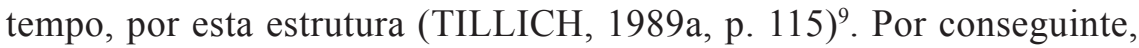
a experiência de sentido individual deve ser compreendida, de acordo com Tillich, como o modo de apresentação de uma relação de determinidade e indeterminidade. Somente quando for possível afirmar que cada experiência individual de sentido representa uma instância de indeterminidade e, deste modo, um excedente de sentido, torna-se possível discorrer sobre a necessidade inescapável do avanço em direção a um contexto de encadeamento sequencial de sentido. O sentido individual deve sempre representar uma estrutura indeterminada de interconexão de sentido, por meio da qual uma atualização ulterior de sentido é alcançada. Em todas as formações, como Tillich afirma precisamente, tanto estéticas quanto lógicas, tanto sociais quanto legais, deve estar contida, portanto, "a reivindicação incondicional da formação absoluta" (TILLICH, 1924, p. 20). Em cada ato de sentido já se encontra posto um horizonte de significância (Sinnhaftigkeit) que não pode ser deduzido dos momentos estruturais forma e substância, mas que se deve, antes, à síntese que Tillich descreve por meio do conceito de sentido.

A significância da estrutura de interconexão de sentido, que é correpresentada em cada sentido particular, não é, contudo, representável em si mesma.

É importante observar agora que este aspecto não constitui algo que poderia se tornar objeto do conhecimento no próprio ato do conhecimento. Onde quer que isto seja intencionado, o terceiro elemento, que jaz além da forma e da matéria, se tornaria, ele mesmo, um material formado. Isso o privaria, no entanto, de seu sentido. (TILLICH, 1989b, p. 280).

\footnotetext{
Nesta conexão, afirma Tillich (1989a, p. 115): „Erkannt ist, was als notwendiges Glied einem Zusammenhang eingeordnet ist. Das Einzelne in seiner Vereinzelung ist kein Gegenstand der Erkenntnis“. Através de sua teoria da Gestalt, Tillich conceitua a precedência da estrutura de interconexão de sentido frente ao sentido individual, uma precedência que não pode se dar, entretanto, à custa do elemento individual de sentido. A estrutura de interconexão de sentido é construída por meio do encadeamento sequencial de cada experiência particular de sentido, e não à parte desta. Sobre este ponto, cf. JAHR, 1989, p. 85-96; HARANT, 2009, p. 142-159.
} 
Com efeito, a significância já é reivindicada em cada ato de sentido, mas ela somente pode ser visualizada em uma forma determinada, e não como ela mesma. A síntese a priori, que é constitutiva para a própria atualização de sentido, somente pode ser tematizada pela consciência, por conseguinte, como síntese a posteriori. Assim, a significância não coincide, portanto, com os fatores estruturais correlativos forma e substância, muito embora seja ela reivindicada em cada realização atual de sentido.

\section{Religião como "Richtung auf das Unbedingte": a consciência sim- bólica e a realização do sentido incondicionado}

A síntese entre forma e substância, enquanto momento já sempre reivindicado no processo de cumprimento de sentido, sistematiza, conforme visto, o modo como a unidade entre a forma do sentido e a substância do sentido é apreendida pelo espírito. Através deste avanço em direção a um contexto sequencial de sentido, triadicamente esquematizado, a experiência pode ser qualificada como dotada de sentido na medida em que passa a ocupar uma posição determinada na estrutura de interconexão de sentido. Por outro lado, a própria experiência se torna, desta forma, determinada por esta mesma estrutura. De acordo com Tillich, a experiência de sentido individual deve ser compreendida nos termos do modo de apresentação de uma relação de determinidade e indeterminidade. A dialética que irrompe desta relação é caracterizada como uma dialética de autoposição e autonegação. Na medida em que a consciência está ciente e tematiza esta relação, ela, a consciência, se torna propriamente religiosa. A significância, que já é reivindicada em cada ato de sentido, somente pode ser realizada, no entanto, em uma forma determinada, e não como ela mesma. É por este motivo que a síntese a priori que é constitutiva para a própria atualização de sentido somente pode ser tematizada pela consciência como síntese a posteriori (DANZ, 2000b, p. 310-311). Aqui, a determinação do conceito de religião no âmbito da teoria do sentido de Tillich se torna apreensível, na medida em que ela, a religião, constitui uma atitude qualitativa da intencionalidade da consciência de sentido. A religião se distingue da cultura na medida em que não apenas sabe da relação de determinidade e indeterminidade que deve ser entendida 
nos termos de uma dialética de autoposição e autonegação, mas também porque ela lida, de forma explícita, com esta dialética. Neste contexto, a determinação do conceito de religião, que Tillich descreve por meio da fórmula "direcionamento ao incondicionado" (TILLICH, 1987b, p. 134), revela o motivo pelo qual o conceito de religião e o conceito de símbolo se pertencem mutuamente.

Religião é o direcionamento do espírito ao sentido incondicionado, cultura é o direcionamento do espírito às formas condicionadas. Ambas se encontram, no entanto, no direcionamento à unidade completa das formas de sentido. Esta unidade é para a cultura a conclusão (Abschluß), mas para a religião ela é um símbolo. Do ponto de vista do incondicionado, este símbolo é afirmado e negado ao mesmo tempo: este é o resultado geral da análise metalógica do sentido. (TILLICH, 1987b, p. 141) ${ }^{10}$.

Em termos programáticos e sistemáticos, a determinação do conceito de religião e da forma do relacionamento entre religião e cultura sobre a base de uma teoria do sentido faz uso de uma dupla intuição (TILLICH, 1987b, p. 133-157). Em primeiro lugar, a fórmula articulada por Tillich demarca o caráter autônomo e transcendental da religião: ela é, como ele afirma em seu Wissenschaftssystem, "o direcionamento imediato do espírito ao incondicionado" (TILLICH, 1989a, p. 209). A demarcação do caráter transcendental da consciência religiosa atesta que, para Tillich, a religião jamais pode ser completamente harmonizada com a cultura sem a estrita perda de sua unicidade distintiva. Antes, o que a fórmula de Tillich evidencia é que a religião se atualiza extrapolativamente na tematização simbólica e imediata da dimensão incondicional de sentido e unidade cuja gênese se encontra em um motivo interno à razão (Vernunft).

Em segundo lugar, e em estreita correlação com a determinação transcendental da religião, a fórmula de Tillich impossibilita uma compreensão da religião nos termos simplistas de uma negação abstrata da cultura. Ao assegurar o caráter transcendental da religião enquanto direcionamento intencional ao sentido incondicionado, a fórmula de Tillich traz consigo, igualmente, a intuição de que a religião possui a

10 Sobre os contornos do método metalógico de Tillich no escopo de seu Wissenschaftssystem, cf. TILLICH, 1989a, p. 211-217. 
função de nomear a irrupção (Durchbruch $)^{11}$ da unidade das funções transcendentais do espírito que se objetivam na cultura. Como Tillich assinala em sua Kulturvortrag de 1919, a religião não é uma função do espírito, mas uma atitude em todas as esferas de sentido "que conecta elementos práticos, teoréticos e intuitivos-emocionais em uma unidade complexa" (TILLICH, 1990a, p. 73). Não há para Tillich, portanto, a possibilidade da afirmação de uma diástase entre religião e cultura. A copertença fundamental entre ambas se encontra na dimensão de incondicionalidade da consciência de sentido. Na medida em que a religião não pode ser compreendida como uma esfera especial de sentido, ou como uma entra outras funções transcendentais do espírito, ela somente é capaz de se atualizar por meio das formas culturais postas pelo espírito. Em sua acepção teórico-sistemática mais própria, a religião deve ser compreendida como o evento de autotransparência do espírito que irrompe por meio das formas culturais, muito embora, sob nenhuma hipótese, seja ela uma função particular de sentido entre outras (TILLICH, 1989a, p. 209). Este evento de autorreflexividade do espírito, implícito na fórmula "direcionamento ao incondicionado", pode ser mais prontamente determinado como o evento em que o espírito se torna evidente para si mesmo em sua atividade cultural, isto é, o evento da "autotransparência na autorrelação da consciência e sua apresentação" (DANZ, 2014, p. 345) ${ }^{12}$. No entanto, por mais que seja verdadeiro afirmar que a religião se torna atual por meio das formas culturais, é ainda mais importante perceber que a religião não pode ser deduzida ou criada na medida em que irrompe para a autoconsciência de um modo inderivável e sempre já concreto ${ }^{13}$. A determinação transcendental do conceito de religião revela que a subjetividade, em sua extrapolação religiosa, se atualiza através de uma assimilação que

11 Para uma breve reconstrução da metáfora "Durchbruch", cf. DANZ, 2007, p. 2-6; SCHARF, 1995, p. 65-81.

12 Para considerações mais entretidas sobre as implicações da determinação do conceito de religião a partir da fórmula Richtung auf das Unbedingte, cf. ABREU, 2017, p. 5-97.

13 No contexto da disputa sobre o "paradoxo", a crítica que Karl Barth dirige à teologia de Tillich a partir da metáfora de um "Offenbarungswalze" revela-se, desta forma, insustentável. Para a crítica de Barth, cf. BARTH, 1962, p. 226-239, especialmente, p. 234. Sobre o debate entre Tillich e Barth no periódico Theologische Blätter, cf. GALLUS, 2007, p. 555-564; SCHÜßLER, 2009, p. 119-129; DANZ, 2011, p. 211-227; WITTEKIND, 2013, p. 89-119; HEINEMANN, 2017, p. 437-454. 
somente irrompe através das formas culturais, de um modo tal que a religião simultaneamente usa e nega estas formas.

A intuição do relacionamento de mútua coexistência e contraposição entre religião e cultura constitui o contexto a partir do qual Tillich introduz seu conceito de símbolo. Por conseguinte, a religião pode ser entendida, desta forma, como "uma realização simbólica do sentido incondicionado" (DANZ, 2000b, p. 341). No símbolo de "Deus", a religião, ou consciência religiosa, realiza a significância de sentido já reivindicada em cada ato de sentido. Com isto, está claro o modo pelo qual a religião se distingue das demais funções transcendentais do espírito: na medida em que a religião transpassa as funções culturais em seu direcionamento intencional à dimensão de profundidade ou de incondicionalidade de sentido, ela realiza simbolicamente o sentido incondicionado ou a significação do sentido. Em contraposição à consciência cultural, a religião é essencialmente, portanto, consciência simbólica. Muito embora a consciência simbólica assuma o sentido incondicionado como uma reivindicação evidentemente atemática, ela não simboliza o sentido incondicionado propriamente dito, mas, antes, modela a realidade através das funções teóricas e práticas.

A partir da determinação da religião como consciência simbólica, a diferença entre religião e cultura se torna passível de apreensão. Esta diferença jaz no fato de que a cultura opera fundamentalmente, para dar lugar a conceitos kantianos, como "esquematização", ao passo que a religião constitui o âmbito próprio da "simbolização" (KANT, $1983, \S 59$, p. $458-463)^{14}$. Esta leitura do relacionamento entre religião

14 O conceito de símbolo desenvolvido por Tillich segue fundamentalmente a distinção entre "simbolização" e "esquematização" tal como por Kant elaborada em sua Kritik der Urteilskraft. Para a distinção entre esquematização e simbolização, veja KANT, 1983, § 59, p. 458-463. Sobre o conceito de símbolo em Kant, cf. SCHÖNRICH, 1981, p. $237-$ 242; DIERKSMEIER, 1998, p. 40-48; p. 85-96; BIELEFELDT, 2003, p. 32-39; RECKI, 2008, p. 189-210; MALY, 2012, p. 21-30; p. 149-203. A confusão entre os conceitos kantianos de esquematização e simbolização na interpretação da teoria dos símbolos de Tillich não é desconhecida na literatura secundária. Um típico exemplo, neste caso, é NÖRENBERG, 1966, p. 175, que interpreta a teoria dos símbolos de Tillich não por meio do conceito kantiano de simbolização, mas, antes, pelo de esquematização. Esta interpretação termina por situar a teoria dos símbolos de Tillich precisamente no lugar que ela quer evitar. Como afirma Nörenberg (1966, p. 175): „Die Schematisierung soll dem reinen transzendentalen Begriff eine empirisch fundierte Verbildlichung ermöglichen, denn wir können uns das Obersinnlich-Transzendente und Göttliche nur durch Analogie 
e cultura constitui o resultado imediato da determinação do conceito de religião a partir da fórmula Richtung auf das Unbedingte. Cultura e religião devem ser distintas na medida em que a cultura constitui o direcionamento intencional do espírito às formas culturais condicionadas, ao passo que a religião é o direcionamento intencional do espírito ao sentido incondicionado. O sentido incondicionado, entretanto, somente pode ser simbolicamente - e não esquematicamente - realizado (DANZ, 2000b, p. 342) ${ }^{15}$. As objetivações do sentido incondicionado por meio das formas condicionadas sempre permanecem sob o juízo da própria dimensão de incondicionalidade constitutiva do espírito. Por conseguinte, a precisação da diferença entre religião e cultura nos termos da distinção kantiana entre esquematização e simbolização justifica, igualmente, a unidade essencial e a distinção atual presente em ambos os polos de intencionalidade para os quais a consciência se dirige (ABREU, 2017, p. 27-48) ${ }^{16}$. Isto porque a religião não possui outra forma para a realização do sentido incondicionado à parte das formas condicionadas (TILLICH, 1989a, p. 230). Segue-se que a diferença entre religião e cultura somente pode encontrar sua justificativa na atitude distintiva da consciência intencional no que diz respeito às

mit der empirischen Wirklichkeit, durch einen Schematismus der Analogie faßlich machen". No contexto de sua interpretação do conceito de símbolo de Tillich, Nörenberg não expõe adequadamente o locus do conceito tillichiano de símbolo a partir da distinção kantiana entre esquematização e simbolização. Somente na introdução de seu estudo, que é dedicado à história do conceito de símbolo, Nörenberg contempla o conceito de símbolo de Kant a partir da terceira crítica. Não obstante, Nörenberg se equivoca ao tratar dos motivos da distinção kantiana entre esquematização e simbolização - a saber, a função do símbolo para a filosofia prática (KRÜGER, 1967, p. 83) - na medida em que avalia os contornos do conceito de símbolo em Kant a partir da doutrina da analogia entis. Sobre este ponto, veja as p. 47-75 do estudo de Nörenberg. Neste sentido, Gunther Wenz (1979, p. 161-190, especialmente, p. 182-183) criticou corretamente a abordagem de Nörenberg ao afirmar de forma categórica: „Die Funktion des Rekurses auf den Kantschen Schematiesierungsgedanken ist dabei keine andere, als diese These zu verdeutlichen. Freilich, mit Kant hat der Nörenbergsche Schematismus genausowenig etwas zu tun, wie der Begriff ,transzendental' mit einer übersinnlich-transzendenten Welt" (WENZ, 1979, p. 182). Os pressupostos kantianos do conceito de símbolo de Tillich também são enfatizados por Wolfgang W. Müller (1990, p. 119). Sobre este ponto, cf., igualmente, DANZ, 2000b, p. 341-347; HEINEMANN, 2017, p. 31-53.

15 Aqui, obviamente, contra a já mencionada interpretação errônea de NÖRENBERG, 1966, p. 175.

16 Nesta conexão, veja, igualmente, NEUGEBAUER, 2011, p. 38-63; CORDEMANN, 2011, p. 94-127; DANZ, 2011, p. 211-227. 
formas culturais condicionadas. A distinção entre ambas jaz, portanto, na qualidade da atitude de intencionalidade da consciência.

\section{O símbolo como apresentação da síntese a priori da consciência de sentido e o duplo absoluto}

Com a determinação da religião enquanto consciência simbólica ou realização simbólica do sentido incondicionado, a fundamentação da teoria da religião de Tillich no âmbito de sua teoria do sentido se torna apreensível. Na medida em que o sentido individual deve sempre representar uma estrutura indeterminada de interconexão de sentido e, desta forma, um excedente de sentido, a dimensão de significância última e unidade da realidade é simbolicamente tematizada pela consciência.

Em toda consciência de sentido estão contidos três elementos: primeiro, a consciência da interconexão de sentido na qual cada sentido particular permanece e sem a qual o sentido se perderia (ohne den er sinnlos würde); segundo, a consciência da significância da interconexão de sentido e, com isso, de cada sentido particular, isto é, a consciência de um sentido incondicionado que está presente em cada sentido particular; terceiro, a consciência de uma reivindicação, sob a qual cada sentido particular permanece, de cumprir o sentido incondicionado (den unbedingten Sinn zu erfüllen). (TILLICH, 1987a, p. 133).

De acordo com a descrição teórica e sistemática da estrutura de interconexão de sentido acima explicitada, torna-se evidente que é precisamente esta significância sempre já reivindicada em cada ato de sentido que Tillich tematiza através de seu conceito de incondicionado. Como Tillich descreve em uma carta enviada em maio de 1918 a Emanuel Hirsch, "o divino é sentido, não ser, e ele é "um outro sentido"" (TILLICH, 1983, p. 126) ${ }^{17}$. Se for possível assumir, com Tillich, que a

17 Em seu artigo Rechtfertigung und Zweifel de 1919, Tillich afirma: „Das Unbedingte ist ein Sinn, aber nicht ein einzelner Sinn, denn jeder einzelne Sinn steht unter dem Zweifel und könnte den Zweifler nicht rechtfertigen. Das Unbedingte ist der Sinn schlechthin, der Ausdruck dafür, daß überhaupt ein Sinn ist, die Setzung der Sinnsphäre. Indem das Ich das Unbedingte bejaht, bejaht es zugleich sich selbst als sinnvoll, erhält es erst einen Sinn“. (TILLICH, 1999, p. 169-170); veja, igualmente, TILLICH, 1990a, p. 74; TILLICH, 1990c, p. 103-107; TILLICH, 1987b, p. 133-141. Neste sentido, cf. ainda os apontamentos de WAGNER, 1973, p. 181, nota 22: „Denn der Zweifel kann sich überhaupt nur dann als Zweifel äußern, wenn er sich schon auf den bezweifelten, damit gleichwohl 
significância incondicionada já está reivindicada em cada experiência de sentido, sem que esta seja capaz, entretanto, de ser representada em si e por si mesma, segue-se que esta circunstância demanda uma forma ainda mais complexa da ideia do absoluto. Esta última deve tomar em consideração não apenas a presença imediata do sentido incondicionado em todas as atualizações de sentido, mas também sua transcendência reflexiva. De acordo com Tillich, o dilema entre a presença imediata do sentido incondicionado em cada atualização de sentido e sua transcendência reflexiva não pode evadir qualquer autoesclarecimento ideativo da consciência de sentido. No entanto, caso se reconheça que este dilema ocorre em cada autoesclarecimento conceitual da consciência, então se torna perceptível que ele se deve precisamente ao paradoxo que assinala a particularidade distintiva da própria ideia do absoluto. Em seu artigo Die Überwindung des Religionsbegriffs in der Religionsphilosophie, de 1922, Tillich explicita de forma inequívoca a transcendência reflexiva intrínseca à ideia do absoluto:

\begin{abstract}
Agora, porém, há um ponto onde o paradoxo não se encontra fundamentado no sujeito, mas, antes, fundamenta-se completamente no objeto, um ponto onde o paradoxo é tão necessário à asseveração quanto a não-contraditoriedade (Widerspruchslosigkeit) é para cada asseveração científico-experiencial: o ponto em que o incondicionado se torna um objeto. O fato que o incondicionado se torna um objeto consiste precisamente no paradoxo original (Urparadoxie), tendo-se em vista que, enquanto incondicionado, ele jaz, em essência, para além da contraposição entre sujeito e objeto. (TILLICH, 1987a, p. 73) ${ }^{18}$.
\end{abstract}

vorausgesetzten Sinn und Sinngrund bezieht. Mit dem Durchbruch der Gewißheit von Sinn, der Grundoffenbarung, durch den Zweifel an sich selber zweifelt". No contexto de suas correspondências com Hirsch entre os anos de 1917 e 1918, Tillich ainda opera uma identificação entre sentido e valor. Como ele afirma nesta mesma carta a Hirsch, “"valor' e 'sentido' resultam, em uma análise mais profunda, como conceitos idênticos" (TILLICH, 1983, p. 125). No entanto, Tillich os diferencia em seu Wissenschaftssystem, mais especificamente, em sua "Doutrina das normas do sentido ou Sistemática [Die Sinnormenlehre oder Systematik]" (TILLICH, 1989a, p. 220-221). A distinção entre sentido e valor é central para o chamado neokantismo de Marburg, cujos representantes principais são Hermann Cohen, Paul Natorp e Ernst Cassirer, enquanto sua identificação é decisiva para a variante do neokantismo de Baden, tal como representada, sobretudo, por Wilhelm Windelband, Heinrich Rickert e Emil Lask. Sobre este ponto, cf. ZIJDERVELD, 2006, p. 1-29; BEISER, 2014, p. 1-9.

18 Neste contexto, cf. TILLICH, 1983, p. 122. Sobre o problema do "duplo absoluto", veja KORSCH, 1996, p. 242-245. 
Caso se procure dissecar conceitualmente o que se poderia dizer com a ideia do paradoxo original ou "profundo" do absoluto, que Tillich indica como a única forma conceitual adequada e possível de descrição do absoluto, é-se conduzido, então, a uma circunstância dupla. O que se torna evidente, com isso, é que, por um lado, Tillich intenciona assegurar a percepção, cum grano salis, kantiana que nega qualquer possibilidade de uma via do condicionado ao incondicionado, e que a reflexão é - por força dos próprios limites impostos à razão crítico-esclarecida - sempre, portanto, malsucedida. Por outro lado, a presença já sempre reivindicada do absoluto nas performances reflexivas da consciência deve ser, ipso facto, validada. A ideia de Tillich em relação ao paradoxo original do absoluto demanda, assim, não apenas a atualização imediata do absoluto, mas também que a transcendência reflexiva do absoluto seja pensada como pertencente ao próprio absoluto.

Como pode ser prontamente percebido, a versão dupla do absoluto que resulta desta elaboração sistemática empreendida por Tillich é uma consequência direta da estrutura peculiar da consciência de sentido. À parte de sua realização concreta, bem como da sobreposição mútua e constante entre dois movimentos opostos que caracteriza o conceito de símbolo elaborado por Tillich, o absoluto jamais é intencionado. No entanto, "uma vez que a consciência não possui quaisquer outras formas além das formas condicionadas, segue-se, então, que ela deve empregá-las", como afirma Tillich, "para expressar o incondicional através delas, isto é, deve empregar os conceitos científicos simbolicamente, e não literalmente" (TILLICH, 1987b, p. 122) ${ }^{19}$. De acordo com a sentença de Tillich, pode-se inferir que o símbolo descreve uma ratio, uma relação de apresentação em que os conceitos científicos não são empregados em sua autenticidade, mas, antes, de forma abertamente inautêntica e indireta $^{20}$. Que os conceitos são empregados em sua inautenticidade

\footnotetext{
Sobre este ponto, cf. também TILLICH, 1989a, p. 229-231.
}

20 Em seu artigo Das religiöse Symbol, de 1928, Tillich afirma que a "inautenticidade [Uneigentlichkeit]" constitui "a primeira e fundamental característica do símbolo". De acordo com Tillich, a inautenticidade demonstra que o ato interno da consciência "que se direciona ao símbolo não intenciona o símbolo enquanto tal, mas, antes, aquilo que é simbolizado nele". Neste caso, afirma Tillich, "o próprio simbolizado pode se tornar símbolo para uma categoria de status superior [höheren Ranges] que é simbolizado no símbolo" (TILLICH, 1987c, p. 213). Não obstante, a demarcação do caráter de inauten- 
e indireticidade é um fato que marca, em primeiro lugar, a diferença peculiar da construção da realidade empírica de sentido. Por outro lado, Tillich também reafirma esta diferença peculiar em seu discurso sobre uma intersecção e correlacionalidade entre o caráter de expressividade e o caráter de validade dos conceitos simbólicos. "Os conceitos metafísicos possuem caráter de expressão [Ausdruckscharakter] e, portanto, caráter de valor [Geltungscharakter], muito embora eles não possu-

ticidade das expressões simbólicas deve ser desenvolvida em conjunto com seu caráter de indireticidade (Indirektheit). Sobre este ponto, cf. HEINEMANN, 2017, p. 508-518. Tillich sublinha este caráter de indireticidade das expressões simbólicas em suas Dogmatik-Vorlesungen proferidas em Dresden entre os anos de 1925 e 1927. No contexto da explicação da inefabilidade do incondicionado, Tillich afirma: „Da nun all unsere Worte ihren Gegenstand in diese Welt einreihen, so ist das Unbedingte zunächst das Unaussprechliche. Spricht es sich nun doch aus, so kann das nur in indirekten Worten, in Symbolen geschehen. Das Symbol hat die Tiefe, daß es die Verborgenheit achtet und doch real auf das Gemeinte hinweist. Auch das Wort Gott ist so ein Symbol“". (TILLICH, 2005, § 4, p. 17). Na condição de "indirekten Worten", os símbolos podem ser designados, desta forma, não apenas como "expressões inautênticas", mas também como "expressões indiretas". Nas características da inautenticidade e indireticidade constitutivas da teoria dos símbolos, a reserva intrínseca aos enunciados simbólicos se articula distintamente em contraste à transgressão sistemática do conceito de imediatidade. É precisamente por meio de sua teoria dos símbolos que o pensamento sistemático de Tillich pode ser "diferenciado das pretensões exageradas da imediatidade" (HEINEMANN, 2017, p. 517-518). Infelizmente, este caráter de indireticidade da concepção simbólica apontado por Tillich não encontra maior reflexão nem em seu Wissenschaftssystem e em sua Religionsphilosophie, por um lado, nem em seu artigo Das religiöse Symbol, de 1928, por outro. Especialmente no que diz respeito a este último artigo, uma identificação explícita da indireticidade enquanto característica constitutiva das expressões simbólicas - em conjunto com as outras características do símbolo apontadas por Tillich (1987c, p. 213-214) - teria contribuído para maior clareza na determinação conceitual de sua teoria dos símbolos. Para uma breve análise das características fundamentais dos símbolos apontadas por Tillich em seu artigo de 1928, cf. HEINEMANN, 2017, p. 455-500; ABREU, 2018, p. 441-451. Além disso, como afirma Heinemann (2017, p. 518), a elucidação da indireticidade das expressões simbólicas "teria prevenido a recepção equívoca de Tillich como o representante de um 'postulado da imediatidade' genuinamente epistemológico". A caracterização de Tillich como o representante de um "Unmittelbarkeitspostulat" epistemológico é desenvolvida por GRUBE, 1998, p. 46-54 no contexto de sua interpretação das obras estadunidenses de Tillich, especialmente em relação ao livro Dynamics of Faith, de 1957. Não obstante, no âmbito de uma reconstrução histórico-genética da teoria dos símbolos de Tillich, a determinação do caráter do conceito de símbolo expresso em suas últimas obras não pode ser simplesmente projetada, sem maior problematização, sobre o período de formação da teoria em análise. Sobre este ponto, cf. HEINEMANN, 2017, p. 514; p. 548-549. Antes, uma investigação das obras ulteriores de Tillich deve tomar com a devida seriedade os contornos fundamentais do conceito de símbolo tal como estes são apresentados no contexto do desenvolvimento de sua teoria. Somente nesta complexidade pode a teoria dos símbolos de Tillich ser verdadeiramente reconstruída em sua profundidade sistêmica. 
am validade no mesmo sentido que os conceitos científicos possuem" (TILLICH, 1989a, 230).

Com este conceito particular de símbolo, Tillich busca assegurar a dificuldade de especificar as condições precisas sob as quais se torna possível interpretar corretamente um conceito como o de símbolo. Posto de forma mais direta, se a consciência possui somente as formas condicionadas à disposição, então ela deve sempre já "saber" que, quando emprega conceitos para representar o sentido incondicionado, ela assim o faz não de uma forma literal, mas sempre e invariavelmente simbólica. Explicar este saber já pressuposto pela consciência é função da teoria do absoluto de Tillich. Assumindo-se a premissa que o processo de sentido deve ser inquestionável para a consciência, não pode haver qualquer possibilidade de que a consciência derive este saber por meio de uma causa externa. Por esta razão, Tillich, em sua Religionsphilosophie de 1925, assume a tarefa de impulsionar a análise filosófica da consciência "até o ponto em que ela apreende a si mesma juntamente com a totalidade da cultura enquanto expressão do religioso" (TILLICH, 1987b, p. 142). A percepção da indivisibilidade do condicionado corresponde à percepção da irredutível relação de reciprocidade entre o incondicionado e o condicionado. A construção perspicaz da indivisibilidade do condicionado, como Tillich a empreende em sua Religionsphilosophie de 1925, constitui igualmente, desta forma, uma construção do condicionado enquanto expressão do incondicionado. Este saber já sempre presente do condicionado tomado em si mesmo como expressão do incondicionado representa a condição indispensável para que a consciência possa entender signos como símbolos. Pois, somente quando a consciência já conhece a si mesma como expressão do incondicionado, pode ela empregar as formas condicionadas simbolicamente.

O símbolo se torna, pois, um conceito quando é interpretado pela consciência como apresentação da síntese a priori. Neste procedimento, o conceito não é mais empregado para designar a construção da realidade de sentido, mas é a própria significância já reivindicada neste procedimento de construção que deve, agora, ser apresentada. Esta diferença, que Tillich aponta como um processo de transição do caráter de valor dos conceitos para o seu caráter de expressão, pode ser explicada como a já mencionada diferença, apresentada por Kant, entre 
simbolização e esquematização. Tendo-se em vista que o sentido não é dado nem de forma ideal nem real (TILLICH, 1924, p. 19), segue-se, portanto, que ele não pode ser esquematizado, mas somente simbolizado. A atualização da significância que a consciência já sempre reivindica em cada realização de sentido não pode depender, enquanto tal, da ajuda de qualquer intuição sensível. Isto porque esta significância não é, evidentemente, nenhuma instância empírica. Assim, a realização do sentido incondicionado somente pode acontecer na medida em que a própria estrutura da atualização de sentido se torna, ela mesma, uma apresentação. Para falar com Kant, trata-se de um modo intuitivo de apresentação, uma hipotipose, que, em contraste com o modo discursivo, encompassa, juntamente com a apresentação esquemática, também uma apresentação de caráter estritamente simbólico. Enquanto sensificação (Versinnlichung), o símbolo é um método ou procedimento de apresentação não esquemático, "já que o conceito é aquele que somente a razão pode pensar e ao qual nenhuma intuição sensível pode ser adequada" (KANT, 1983, § 59, p. 459). Neste último caso, como afirma Kant,

o conceito é fornecido com uma intuição tal que o procedimento da faculdade do juízo é simplesmente dado de forma analógica àquilo que ele observa na esquematização, isto é, vem em acordo com ele simplesmente em função da regra deste procedimento, não em função da própria intuição, e, consequentemente, apenas em função da forma da reflexão, não do conteúdo. (KANT, 1983, § 59, p. 459)²1.

Nesta direção, e em conformidade com uma perspectiva que poderia ser descrita, em alguma medida, como semiótica, pode-se afirmar, com base na propícia distinção kantiana entre simbolização e esquematização, que "o símbolo é um signo no qual o próprio emprego do

${ }_{21}$ Como afirma Kant (1983, § 59, p. 459): „Alle Hypotypose (Darstellung, subiectio sub adspectum), als Versinnlichung, ist zwiefach: entweder schematisch, da einem Begriffe, den der Verstand faßt, die korrespondierende Anschauung a priori gegeben wird; oder symbolisch, da einem Begriffe, den nur die Vernunft denken, und dem keine sinnliche Anschauung angemessen sein kann, eine solche untergelegt wird, mit welcher das Verfahren der Urteilskraft demjenigen, was sie im Schematisieren beobachtet, bloß analogisch, d.i. mit ihm bloß der Regel dieses Verfahrens, nicht der Anschauung selbst, mithin bloß der Form der Reflexion, nicht dem Inhalte nach, übereinkommt“. Sobre este ponto, cf. DIERKSMEIER, 1998, p. 42-43. 
signo opera como signo" (DANZ, 2000b, p. 346) $)^{22}$. A apresentação simbólica consiste, desta forma, não na ilustração de uma realidade, mas na apresentação do próprio processo da atualização da consciência de sentido ${ }^{23}$. O que Tillich busca é, em outras palavras, nada menos que a superação da clivagem irresolúvel entre o sentido incondicionado e o processo de cumprimento do sentido condicionado. Por esta razão, cada sentido contém um excedente de sentido, que Tillich descreve, aptamente, como "significado transcendente [transzendentes Bedeutung]" (TILLICH, 1992, p. 138). "O sagrado não é inintuível [das Heilige ist nicht unanschaulich]. Contudo, ele não é objetivo. O sagrado é intuído de forma não-objetiva; ele é intuído como significado transcendente" (TILLICH, 1992, p. 138). O conceito de símbolo elaborado por Tillich descreve, assim, um estado de coisas em que a significância reivindicada pelos sujeitos finitos em cada ato particular de sentido não pode ser realizada por si mesma. Antes, a significância encontra sua realização na própria apresentação do processo de atualização de sentido. Assim, na medida em que os símbolos religiosos são constituídos, enquanto tais, nas performances mentais da consciência religiosa, a teoria dos símbolos de Tillich demonstra ser, antes de tudo, uma "teoria da simbolização" (HEINEMANN, 2017, p. 548). A significância de sentido já reivindicada em cada ato de sentido é realizada na própria estrutura de apresentação do processo de atualização de sentido. Em sua transcendência interna, os símbolos devem ser considerados, ao mesmo tempo, como uma

22 Enquanto modo indireto de apresentação, a hipotipose simbólica faz uso de uma "analogia qualitativa” (DIERKSMEIER, 1998, p. 41-43) na medida em que não são os componentes intuíveis dos símbolos que são transferidos a outros objetos, mas a relação dos componentes com "os objetos suprassensíveis" intuídos nos símbolos. Como afirma Dierksmeier (1998, p. 43), “o símbolo não é, portanto, cumprido na intuição, mas na reflexão sobre essa relação". Sobre o método analógico em Kant, veja PIEPER, 1996, p. 106. De acordo com sua apropriação da teoria dos símbolos de Kant, o conceito de símbolo elaborado por Tillich tem a função de apresentar, em sua própria performance de simbolização, o processo de atualização de sentido. Sobre este ponto, veja, igualmente, HEINEMANN, 2017, p. 548-549.

23 A proximidade entre a teoria dos símbolos de Tillich e a teoria dos símbolos de Kant é, neste sentido, prontamente perceptível. Pois, também para Kant, como bem aponta Dierksmeier, o símbolo não encontra sua validade teórica em uma suposta apreensão de uma substância transcendente, mas em sua própria função transcendental de simbolização. Nas palavras de Dierksmeier (1998, p. 92): „Denn das Symbol hat seine geltungstheoretische Seinsquelle in seiner (transzendentalen) Funktion, nicht aber in einer ihm innewohnenden transzendenten Substanz". Sobre este ponto, veja, igualmente, BIELEFELDT, 2003, p. 32-39. 
expressão da absoluta transcendência da ideia do incondicionado. É, pois, no símbolo, enquanto modo de apresentação do próprio processo de atualização de sentido, que a consciência realiza tanto a diferença quanto a unidade entre o incondicionado e o condicionado.

\section{O símbolo como forma religiosa de apresentação do absoluto e a quebra da consciência mítica em sua imediatidade}

Embora apenas esboçada como resultado da natureza particular de sua teoria do sentido, a teoria do absoluto desenvolvida por Tillich revela, precisamente por conduzir à ideia de um duplo absoluto, que a função teórica do símbolo possui um lugar de indiscutível proeminência em sua teoria da subjetividade, na medida em que é no símbolo que, para Tillich, ocorre o esclarecimento de que a gênese autovelada da consciência se encontra nela mesma. O processo de esclarecimento da significância incondicionada já sempre reivindicada pela subjetividade finita em cada um de seus atos reflexivos somente é possível, contudo, como um processo de interpretação. É aqui que, na teoria de Tillich, o papel da religião se torna mais visível. Posto de forma mais precisa, a execução deste processo interpretativo da facticidade de si, que não pode ser elucidado pela própria consciência, constitui a função mais particular da religião. No esboço original de sua Kulturvortrag de 1919, Tillich afirma:

Religião é a experiência do incondicionado, e isso significa a presença da realidade absoluta fundada sobre a experiência do nada absoluto; experiencia-se o nada dos entes, o nada dos valores, o nada da vida pessoal; onde esta experiência é conduzida ao nada de um não radical, absoluto, aí ela é revertida na experiência igualmente absoluta da realidade, em um sim radical. (TILLICH, 2008, p. 41).

Em conformidade com esta definição preliminar oferecida por Tillich, a religião é o lugar onde a síntese fundamental de todas as funções da consciência é tematizada de forma a priori. Por esta mesma razão, ela própria não pode ser, como Tillich reiteradas vezes acentua, uma função da consciência, que permaneceria, neste caso, ao lado das ou- 
tras funções transcendentais do espírito (TILLICH, 1987b, p. 141) ${ }^{24}$. Na condição de locus da síntese apriorística das funções transcendentais do espírito, a religião representa, antes de tudo, a significância das funções propriamente ditas da consciência. A apresentação desta "relação com o incondicional-transcendente" (TILLICH, 1987c, p. 217) constitutiva da própria consciência se efetiva, como se pode inferir, por meio do símbolo ou da linguagem simbólica. Contudo, nesta determinação, uma nova categoria aparece, na medida em que Tillich descreve este processo simbólico de representação da relação da consciência subjetiva com o incondicional-transcendente como "mito". O mito é, para Tillich, a quintessência daqueles símbolos em que "o incondicional-transcendente é intuído de forma direta ou indireta" (TILLICH, 1987c, p. 220). Os símbolos conformam, em um sentido estrito, as formas religiosas de apresentação do absoluto, uma vez que somente neles é a síntese constitutiva da consciência religiosa propriamente dita realizada de modo a priori.

$\mathrm{O}$ autoesclarecimento da presença do absoluto em cada ato da consciência e a determinação da diferença entre o sentido incondicionado e o cumprimento finito de sentido constituem dois resultados centrais da realização da síntese a priori da consciência religiosa. Com base nestes dois aspectos, uma teoria dos símbolos é articulada, e Tillich a caracteriza como "simbólico-realista" (TILLICH, 1987d, p. 230). A partir desta concepção do símbolo religioso, Tillich afirma ser capaz de superar sistematicamente a alternativa entre uma teoria metafísica e uma teoria epistemológica do mito (TILLICH, 1987d, p. 230) ${ }^{25}$. Contra

24 Como afirma Tillich (1987b, p. 141): „Die Religion ist also keine Sinnfunktion neben den übringen. Das folgt unmittelbar aus ihrem Charakter als Richtung auf das Unbedingte. Sie, die in allen Sinnfunktionen grundlegend ist, kann selbst keine Sinnfunktion sein“". Sobre este ponto, cf., igualmente, TILLICH, 1959, p. 3-9.

25 Na concepção de Tillich, Schelling é o representante por excelência da teoria metafísica do mito, ao passo que Cassirer aparece como um expoente de uma teoria epistemológica do mito (TILLICH, 1987d, p. 230). Essa distinção não resiste, contudo, a uma análise imanente da posição de Cassirer. Em seu artigo Schelling und die Anfänge des existentialistischen Protestes (1989c, p. 391-402, especialmente, p. 393), Tillich revisa, parcialmente, sua visão de Cassirer. Não obstante, em contraste à alternativa entre a teoria epistemológica e teoria metafísica do mito, Cassirer situa sua teoria do pensamento mítico a partir de uma análise da interpretação metafísica de Schelling e da interpretação empírica de Wilhelm Wundt. Sobre este ponto, cf. CASSIRER, 2010, p. 1-33. Para uma análise do conceito de símbolo de Cassirer, veja MEYER-BLANCK, 2000, p. 91-99; HEINEMANN, 2017, p. 14-31. Para uma comparação entre o conceito de símbolo no pensamento de Tillich $\mathrm{e}$ Cassirer, cf. DANZ, 2000a, p. 201-228. 
a interpretação epistemológica do mito, Tillich afirma que o símbolo não pode ser uma imagem de uma realidade existente, mas somente um produto da consciência. Como ele afirma, o mito "não possui a realidade da imagem; pois, o mito vive nos símbolos, que certamente não são arbitrários, mas estão sujeitos, de acordo com a apreensão do incondicionado, a uma legalidade determinada - e, para além disto, a uma legalidade universal" (TILLICH, 1987d, p. 230). A consciência não se direciona para objetos que são externos a ela, mas para os correlatos intencionais de seus atos. Não obstante, os símbolos com os quais a consciência representa o absoluto, que, enquanto absoluto é, para ela mesma, constitutivo, não são nem arbitrariamente inventados, por um lado, nem encontram sua justificativa em um "convencionalismo"26, por outro. Antes, estes símbolos são condicionados por uma determinada situação sociocultural e pela estrutura de interconexão de sentido que é constitutiva para toda consciência. Muito embora a ideia de uma correlação contínua entre forma e substância dê lugar a uma interpretação mais ampla, tendo-se em vista que o sentido incondicionado permite, em princípio, ser representado por qualquer forma, a representação fática, no entanto, na medida em que é condicionada pelas formas culturais, é limitada (DANZ, 2000b, p. 348-349).

A simbolização do absoluto nas formas condicionadas da consciência, isto é, a simbolização do incondicionado através das formas condicionadas, pressupõe tanto a presença do absoluto na atualização imediata da consciência, por um lado, quanto um saber deste absoluto que irrompe a partir deste processo, por outro. À parte deste saber, a diferença entre imagem e sentido não seria assinalável e, portanto, a própria irrupção de um processo de simbolização seria completamente incompreensível. A percepção desta distinção, que representa, em si mesma, um momento constitutivo do próprio processo simbólico, é a

26 A rejeição de um convencionalismo é baseada na distinção de Tillich entre símbolo e signo. Sobre este ponto, cf. Tillich (1987c, p. 213): „Das dritte Merkmal des Symbols ist die Selbstmächtigkeit. Sie besagt, daß das Symbol eine ihm selbst innewohnende Macht hat, die es von dem bloßen in sich ohnmächtigen Zeichen unterscheidet. Dieses Merkmal ist maßgebend für die Trennung von Symbol und Zeichen". Para a distinção tillichiana entre símbolo e signo, veja HEINEMANN, 2017, p. 479-498. Cassirer também rejeita uma posição convencionalista em sua teoria do mito, do símbolo e dos signos. Sobre este ponto, veja CASSIRER, 1990, p. 21. Nesta conexão, cf., igualmente, KROIS, 1988, p. 22. 
verdade indispensável da teoria metafísica do mito: "o mito tem realidade, pois ele é julgado pelo incondicional-real" (TILLICH, 1987d, p. 230). Não obstante, quanto mais a interpretação epistemológica do mito se torna capaz de explicar o fato de que os mitos são um resultado da conquista da atividade produtiva da consciência, menos esta interpretação consegue explicar como o processo simbólico, de fato, se inicia. Assim, na leitura de Tillich, a interpretação epistemológica termina por obliterar a realidade peculiar do mito enquanto um elemento constitutivo "do espiritual propriamente dito" (TILLICH, 1987c, p. 220). Em contrapartida, a interpretação metafísica do mito corre o risco de se agarrar à substância da realidade que no mito é apresentada. Por sua tendência de se dirigir unilateralmente ao elemento estrutural da substância, a interpretação metafísica do mito não faz jus ao fato de que a substância sempre já se encontra invariavelmente unida com uma forma. Neste sentido, teorias metafísicas e epistemológicas do mito revelam-se, no juízo de Tillich, como rupturas e dissoluções unilaterais da correlação permanente dos momentos estruturais do sentido. A quebra desta correlação invariável entre forma e substância implica, por necessidade, a quebra da própria consciência de sentido.

Como corolário destas considerações, temos que a teoria "simbólico-realista" do mito desenvolvida por Tillich se caracteriza fundamentalmente por conferir ao conjunto de símbolos, ou mais precisamente, ao mito, enquanto forma religiosa de expressão do absoluto, uma função constitutiva para o espírito como tal. Posto de forma mais direta, o mito é a forma em que a consciência percebe que sua relação com o absoluto é constitutiva para si mesma. No entanto, esta apresentação da relação do propriamente religioso com o incondicional-transcendente é sempre já dependente do correlato intencional dos atos da consciência, por virtude dos quais o mundo objetivo é fenomenologicamente construído. Tillich descreve esta relação nos termos de um entrelaçamento entre o religioso, o científico e o mítico (TILLICH, 1987c, p. 220). Se a forma do mito é, com isso, inscrita em cada consciência enquanto tal, então a pergunta pelo modo como a interrelação entre a tríade "religião-ciência-mito" é estruturada se torna, por sua vez, ainda mais urgente. Segue-se que o entendimento de uma história do espírito e da cultura que se encontra fundamentada na ideia de que religião e ciência 
se desenvolvem a partir do mito e, com isso, o superam, está excluído da concepção de Tillich ab ovo et initio (TILLICH, 1987c, p. 220) ${ }^{27}$. Em contraposição a uma história da cultura de caráter e inspiração evolucionista-positivista, religião, ciência e mito somente podem ser vistos, de acordo com Tillich, a partir de uma relação de permanente entrelaçamento e interação: nunca, portanto, de forma isolada. Isto porque aquilo que no mito se encontra fundamentado não pode, por motivos lógicos, superá-lo (DANZ, 2000b, p. 350). No entanto, caso se deseje manter a ideia de uma diferenciação da consciência mítica, bem como a ideia de que o mito possui uma função constitutiva para a consciência eo ipso, então há que se sublinhar que tais ideias não podem ser adequadamente desenvolvidas nos modos de uma contraposição entre a perspectiva genética e a teoria da validade ${ }^{28}$. Em vez de se agarrar a uma oposicionalidade entre a história do desenvolvimento e a teoria da validade do mito, Tillich sustenta que o próprio mito é constitutivamente marcado por uma "dialética interna" (TILLICH, 1987c, p. 219). "A tensão se dissolve tão logo se torna manifesto que o mito não foi encerrado, mas que apenas sua forma foi alterada" (TILLICH, 1987c, p. 218). A fórmula da "dialética interna" do mito tem a finalidade básica de transformar esta coexistência cheia de tensões, oriunda de uma contraposição entre a perspectiva genética e a teoria da validade, em uma unidade não idêntica, isto é, uma síntese aberta e em permanente devir. Trata-se, portanto, de transformar a coexistência cheia de tensões que caracteriza o entrelaçamento entre ambas as perspectivas em uma unidade marcada por uma tensão interna que permanece, entretanto, não-suprassumível.

De acordo com esta diferenciação interna, que Tillich traz à expressão por meio da ideia de uma dialética interna do mito, torna-se evidente que mito e religião não podem simplesmente permanecer lado a lado. A ideia de uma dialética interna do mito requer um entrelaçamento

27 Uma progressão do mito para o logos ou ciência (Wissenschaft), tal como representada por Hegel, é, assim, absolutamente rejeitada por Tillich. Para a determinação de Hegel da relação entre consciência natural e ciência (isto é, filosofia), cf. HEGEL, 2011, p. 57-68.

28 Tal contraposição entre a perspectiva genética e a teoria da validade, Tillich acredita, erroneamente, ser capaz de localizar na teoria do símbolo e do mito de Cassirer. Sobre este ponto, cf. TILLICH, 1987c, p. 218. Ainda sobre este ponto, cf. HEINEMANN, 2017, p. 14-31. 
tão minucioso entre mito e religião que a religião deve ser entendida como um momento do mito e o mito como um momento da religião (DANZ, 2000b, p. 351). O entrelaçamento entre mito e religião é, assim, transposto para a dialética interna da consciência mítico-religiosa. Para dar lugar à supracitada formulação de Tillich uma vez mais, o mito não se encerra simplesmente na religião; antes, ele apenas altera sua forma. Esta alteração de forma, que o elemento mítico experiencia na consciência religiosa, é explicada por Tillich como uma quebra (Durchbrechung) do "mito em sua imediatidade" (TILLICH, 1987c, p. 218 ${ }^{29}$. A diferença entre mito e religião não jaz, portanto, em seus conteúdos, mas em uma alteração da posição da consciência em relação a tais conteúdos por ela agarrados. Isto porque a consciência somente pode apreender uma posição alterada em relação a seus conteúdos na medida em que ela se diferencia deles. É, pois, neste sentido que Tillich designa a consciência que se percebe distinta de seus conteúdos como “consciência transcendental" (TILLICH, 1987d, p. 231) 30. Introduz-se na dinâmica da consciência subjetiva, desta forma, a reflexividade, por meio da qual um conhecimento da diferença entre símbolo e sentido pode, enfim, emergir. Em função desta reflexividade, que somente podemos designar como "avultada", a consciência religiosa pode fazer uso "de seus conteúdos sob a constante recordação de seu caráter simbólico e de sentido, que ela expressa de forma intuitiva e vívida, muito embora inadequada" (TILLICH, 1999, p. 172) ${ }^{31}$. Na medida em

29 Sobre este ponto, cf., igualmente, TILLICH, 1987d, p. 230-236.

30 No contexto da determinação tillichiana da consciência que sabe ser distinta de seus conteúdos como consciência transcendental, Hans Loof $(1955$, p. 61) afirma erroneamente que "Tillich confunde o ato da fé peculiarmente religioso com a filosofia da religião". A crítica de Loof é, entretanto, injustificável. Na medida em que não tematiza a reflexividade específica que caracteriza a consciência religiosa, Loof não consegue apontar a distinção entre a consciência mítica e a consciência transcendental. A quebra do mito em sua imediatidade constitui condição indispensável para a autodeterminação da consciência enquanto consciência propriamente religiosa. Este erro de Loof se reflete em sua indicação de que Tillich não teria enfatizado com a devida força a contraposição entre a dialética da fé e a dialética simbólica. Sobre este ponto, cf. LOOF, 1955, p. 59.

31 Como afirma Tillich (1999, p. 172): ,Sobald sich das Bewußtsein aber auf die Stufe des radikalen Zweifels erhoben hat, können jene Vergegenständlichungen in ihrer unreflektierten Anschaulichkeit nur als Symbole gelten für die Lebendigkeit und Konkretheit des absoluten Paradox. Auf dieser Stufe kann das Bewußtsein jene Symbole nur gebrauchen unter ständiger Erinnerung an ihren symbolischen Charakter und den Sinn, den sie zwar anschaulich und lebendig, aber doch inadäquat ausdrücken“". 
que reconhece o caráter simbólico dos símbolos, a consciência religiosa "quebra", por assim dizer, a imediatidade das representações míticas. A diferença entre a consciência mítica quebrada e não quebrada pode ser elucidada, portanto, como a diferença entre uma forma de consciência que está ciente do caráter simbólico de suas representações e outra que não está. A consciência mítica não quebrada assume os correlatos objetivos de seus atos espirituais como coisas em si mesmas, ao passo que a consciência mítica quebrada sabe que suas imagens simbólicas representam, de forma inautêntica e indireta, o sentido incondicionado. Além disso, a consciência mítica quebrada sabe, sobre o fundamento da estrutura da consciência, que somente pode trazer o incondicionado à realização por meio das formas condicionadas da consciência. Pois, como afirma Tillich, "a transcendência incondicionada não é, enquanto tal, intuível. Caso se torne intuível - e ela deve tornar-se tal na religião -, ela somente pode assim se tornar através de representações míticas" (TILLICH, 1987c, p. 219).

Quanto mais a consciência mítica quebrada representa um ganho em autodiferenciação, o que significa sempre e invariavelmente um aumento em abstração, menos é ela capaz de evadir-se das representações míticas. Isto porque a religião somente pode articular-se de uma forma tal que ela substitui os conteúdos imediatos negados em sua autodiferenciação por outros conteúdos. O conceito de "princípio protestante" elaborado por Tillich encontra sua função teórica mais própria precisamente quando aplicado como recurso de validade para esta unidade de autonegação e autoposição, ou ainda, crítica e formação (TILLICH, 1992, p. 127-149). Na medida em que o conhecimento sobre a diferença entre símbolo e sentido caracteriza a consciência religiosa, e na medida em que esta consciência opera através da diferença entre um processo permanente de autonegação e autoposição, crítica e formação, a religião adquire uma função decisiva para o processo cultural em sua totalidade. A originalidade específica da religião se baseia no fato que ela lida com uma esfera de sentido e significação, por natureza, não tematizável em outras funções culturais, ainda que esta esfera também não seja, por seu turno, tematizável à parte destas funções. Em sua atualização de autonegação e autoposição, crítica e formação, a religião atesta a unidade e diferença entre o condicionado e o incondicionado. 
Neste sentido, a religião não faz apenas uma contribuição indispensável aos processos de formação cultural. Antes, na intenção de realizar esta tarefa, ela deve, ipso facto, permanecer distinta da cultura.

Conforme visto, o relacionamento entre religião e cultura se articula no conceito de símbolo. Na medida em que o conceito de símbolo aponta para a performance específica da religião, e na medida em que ele busca tematizar a sempre já reivindicada significância de sentido de uma forma tal que saiba que cada um de seus símbolos permanece por trás de cada tematização, o símbolo deve ser categoricamente distinto de outras formas de apresentação. A religião, enquanto sistema de autointerpretação simbólica, encontra sua justificativa na medida em que tematiza o sentido incondicionado ou a significação do sentido de forma invariavelmente simbólica, isto é, de uma forma sempre inautêntica e indireta.

\section{Referências}

\section{Obras de Paul Tillich}

TILLICH, Paul. Zu Tillichs Systematik. Tillichs Antwort. Blätter für Religiösen Sozialismus, Jahrgang 5, No. 5-6, p. 18-22, 1924.

. Religion as a Dimension in Man's Spiritual Life. In: KIMBALL, Robert C. (Ed.). Theology of Culture. London; Oxford; New York: Oxford University Press, 1959, p. 3-9.

. „Die Kategorie des „Heilige“ bei Rudolf Otto“. (1923). In: ALBRECHT, Renate. (Hg.). Gesammelte Werke. Band XII: Begegnungen. Paul Tillich über sich selbst und andere. Stuttgart: Evangelisches Verlagswerk, 1971, p. 184-186.

. Paul Tillich - Emanuel Hirsch. Die große religionsphilosophische Debatte. In: ALBRECHT, R.; TAUTMANN, René. (Hg.). Ergänzungs- und Nachlaßbände zu den Gesammelten Werken von Paul Tillich. Band VI: Briefwechsel und Streitschriften. Theologische, philosophische und politische Stellungnahmen und Gespräche. Frankfurt am Main: Evangelisches Verlagswerke, 1983, p. 95-136.

. Die Überwindung des Religionsbegriffs in der Religionsphilosophie. (1922). In: CLAYTON, John Powell. (Hg.). Main Works - Hauptwerke. Band 4: Religionsphilosophische Schriften. Berlin; New York: Walter de Gruyter; Evangelisches Verlagswerk, 1987a, p. 73-90. 
. Religionsphilosophie. (1925). In: CLAYTON, John Powell. (Hg.). Main Works - Hauptwerke. Band 4: Religionsphilosophische Schriften. Berlin; New York: Walter de Gruyter; Evangelisches Verlagswerk, 1987b, p. 117-170.

. Das religiöse Symbol. (1928). In: CLAYTON, John Powell. (Hg.). Main Works - Hauptwerke. Band 4: Religionsphilosophische Schriften. Berlin; New York: Walter de Gruyter; Evangelisches Verlagswerk, 1987c, p. 213-228.

. Mythus und Mythologie. (1930). In: CLAYTON, John Powell. (Hg.). Main Works - Hauptwerke. Band 4: Religionsphilosophische Schriften. Berlin; New York: Walter de Gruyter; Evangelisches Verlagswerk, 1987d, p. 229-236.

The Meaning and Justification of Religious Symbols. (1961). In: CLAYTON, John Powell. (Hg.). Main Works - Hauptwerke. Band 4: Religionsphilosophische Schriften. Berlin; New York: Walter de Gruyter; Evangelisches Verlagswerk, 1987e, p. 415-420.

. Das System der Wissenschaften nach Gegenständen und Methoden. (1923). In: WENZ, Gunther. (Hg.). Main Works - Hauptwerke. Band 1: Philosophische Schriften. Berlin; New York: Walter de Gruyter; Evangelisches Verlagswerk, 1989a, p. 113-263.

. Kairos und Logos. Eine Untersuchung zur Metaphysik der Erkenntnis. (1926). In: WENZ, Gunther. (Hg.). Main Works - Hauptwerke. Band 1: Philosophische Schriften. Berlin; New York: Walter de Gruyter; Evangelisches Verlagswerk, 1989b, p. 265-305.

. Schelling und die Anfänge des existentialistischen Protestes. (1955). In: WENZ, Gunther. (Hg.). Main Works - Hauptwerke. Band 1: Philosophische Schriften. Berlin; New York: Walter de Gruyter; Evangelisches Verlagswerk, 1989c, p. 391-402.

Über die Idee einer Theologie der Kultur. (1919). In: PALMER, Michael. (Hg.). Main Works - Hauptwerke. Band 2: Kulturphilosophische Schriften. Berlin; New York: Walter de Gruyter; Evangelisches Verlagswerk, 1990a, p. 69-85.

. Religiöser Stil und religiöser Stoff in der bildenten Kunst. (1921). In: PALMER, Michael. (Hg.). Main Works - Hauptwerke. Band 2: Kulturphilosophische Schriften. Berlin; New York: Walter de Gruyter; Evangelisches Verlagswerk, 1990b, p. 87-99.

. Kirche und Kultur. (1924). In: PALMER, Michael. (Hg.). Main Works - Hauptwerke. Band 2: Kulturphilosophische Schriften. Berlin; New York: Walter de Gruyter; Evangelisches Verlagswerk, 1990c, p. 101-114. 
. Der Protestantismus als kritisches und gestaltendes Prinzip. (1929). In: HUMMEL, Gert. (Hg.). Main Works - Hauptwerke. Band 6: Theologische Schriften. Berlin; New York: Walter de Gruyter; Evangelisches Verlagswerk, 1992, p. 127-149.

Rechtfertigung und Zweifel. (1919). In: STURM, Erdmann. (Hg.). Ergänzungs- und Nachlaßbände zu den Gesammelten Werken von Paul Tillich. Band X: Religion, Kultur, Gesellschaft. Unveröffentlichte Texte aus der deutschen Zeit (1908-1933). Erster Teil. Berlin; New York: Walter de Gruyter GmbH \& Co. KG, 1999, p. 127-230.

. Dogmatik-Vorlesung. (Dresden 1925-1927). In: SCHÜßLER, Werner; STURM, Erdmann. (Hg.). Ergänzungs- und Nachlaßbände zu den Gesammelten Werken von Paul Tillich. Band XIV. Berlin; New York: Walter de Gruyter GmbH \& Co., KG, 2005.

. Über die Idee einer Theologie der Kultur. (1919). In: DANZ, Christian; SCHÜßLER, Werner; STURM, Erdmann. (Hg.). Paul Tillich. Ausgewählte Texte. Berlin; New York: Walter de Gruyter GmbH \& Co. KG, 2008, p. 25-41.

\section{Literatura secundária}

ABREU, Fábio Henrique. "Richtung auf das Unbedingte" and "Self-Transparency": The Foundations of Paul Tillich's Philosophy of Spirit, Meaning, and Religion (1919-1925). Revista Eletrônica Correlatio, vol. 16, no. 1, p. 5-97, 2017.

Símbolo como linguagem da religião: fundamentos da teoria dos símbolos no âmbito da teoria da religião de Paul Tillich. In: TADA, Elton Sadao; SOUZA, Vitor Chaves. Paul Tillich e a linguagem da religião. Santo André: Kapenke, 2018, p. 365-582.

BARTH, Karl. Von der Paradoxie des ,positiven Paradoxes“: Antworten und Fragen an Paul Tillich. In: ALBRECHT, Renate. (Hg.). Gesammelte Werke. Band VII: Der Protestantismus als Kritik und Gestaltung. Schriften zur Theologie I. Stuttgart: Evangelisches Verlagswerk, 1962, p. 226-239.

BEISER, Frederick C. The Genesis of Neo-Kantianism, 1796-1880. Oxford; New York: Oxford University Press, 2014.

BIELEFELDT, Heiner. Symbolic Representation in Kant's Practical Philosophy. Cambridge: Cambridge University Press, 2003.

CASSIRER, Ernst. Die Begriffsform im mythischen Denken. In: Wesen und Wirkung des Symbolbegriffs. Darmstadt: Wissenschaftliche Buchgesellschaft, 1990, p. 1-70. 
. Philosophie der symbolischen Formen. Zweiter Teil: Das mythische Denken. Hamburg: Felix Meiner Verlag GmbH, 2010.

CORDEMANN, Claas. Religion und Kultur. Paul Tillichs religionsphilosophische Grundlegung einer Theologie der Kultur. In: DANZ, Christian; SCHÜßLER, Werner. (Hg.). Paul Tillichs Theologie der Kultur: Aspekte, Probleme, Perspektiven. Berlin; Boston: Walter de Gruyter GmbH \& Co. KG, 2011, p. 94-127.

DANZ, Christian. Der Begriff des Symbols bei Paul Tillich und Ernst Cassirer. In: KORSCH, Dietrich; RUDOLPH, Enno. (Hg.). Die Prägnanz der Religion in der Kultur: Ernst Cassirer und die Theologie. Tübingen: J. C. B. Mohr (Paul Siebeck), 2000a, p. 201-228.

. Religion als Freiheitsbewußtsein. Eine Studie zur Theologie als Theorie der Konstitutionsbedingungen individueller Subjektivität bei Paul Tillich. Berlin; New York: Walter de Gruyter, 2000b.

. Breakthrough of the Unconditional: Tillich's Concept of Revelation as an Answer to the Crisis of Historicism. Bulletin of the North American Paul Tillich Society, vol. 33, no. 2, p. 2-6, 2007.

. Die Religion in der Kultur. Karl Barth und Paul Tillich über die Grundlagen einer Theologie der Kultur. In: DANZ, Christian; SCHÜßLER, Werner. (Hg.). Paul Tillichs Theologie der Kultur: Aspekte, Probleme Perspektiven. Berlin; Boston: Walter de Gruyter GmbH \& Co. KG, 2011, p. 211-227.

. Zwischen Transzendentalphilosophie und Phänomenologie. Die methodischen Grundlagen der Religionstheorien bei Otto und Tillich. In: LAUSTER, Jörg; SCHÜZ, Peter; BARTH, Roderich; DANZ, Christian. (Hg.). Rudolf Otto. Theologie - Religionsphilosophie - Religionsgeschichte. Berlin; Boston: Walter de Gruyter GmbH, 2014, p. 335-345.

DIERKSMEIER, Claus. Das Noumenon Religion. Eine Untersuchung zur Stellung der Religion im System der praktischen Philosophie Kants. Berlin; New York: Walter de Gruyter GmbH \& Co., 1998.

GALLUS, Petr. Der Mensch zwischen Himmel und Erde. Der Glaubensbegriff bei Paul Tillich und Karl Barth. Leipzig: Evangelische Verlaganstalt, 2007.

GRUBE, Dirk-Martin. Unbegründbarkeit Gottes? Tillichs und Barths Erkenntnistheorien im Horizont der gegenwärtigen Philosophie. Marburg: N. G. Elwert Verlag, 1998.

HAIGIS, Peter. Im Horizont der Zeit. Paul Tillichs Projekt einer Theologie der Kultur. Marburg: N. G. Elwert Verlag, 1998.

HARANT, Martin. Religion - Kultur - Theologie. Eine Untersuchung zu ihrer Verhältnisbestimmung im Werke Ernst Troeltschs und Paul Tillichs im Vergleich. Frankfurt am Main: Peter Lang GmbH, 2009. 
HEGEL, Georg Wilhelm Friedrich. Phänomenologie des Geistes. Neu herausgegeben von Hans Friedrich Wessels und Heinrich Clairmont. Hamburg: Felix Meiner Verlag GmbH, 2011.

HEINEMANN, Lars Christian. Sinn - Geist - Symbol: Eine systematisch-genetische Rekonstruktion der frühen Symboltheorie Paul Tillichs. Tillich-Forschungen: Band 10. Berlin; Boston: Walter de Gruyter GmbH, 2017.

HERBERGER, Kurt. Historismus und Kairos. Die Überwindung des Historismus bei Ernst Troeltsch und Paul Tillich. Theologische Blätter, vol. 14, Nr. 18, p. 129-141; p. 161-175, 1935.

JAHR, Hannelore. Theologie als Gestaltmetaphysik: die Vermittlung von Gott und Welt im Frühwerk Paul Tillichs. Berlin; New York: Walter de Gruyter, 1989.

KANT, Immanuel. Kritik der Urteilskraft. In: WEISCHEDEL, Wilhelm. (Hg.). Immanuel Kant. Werke in zehn Bänden. Sonderausgabe. Band 8: Kritik der Urteilskraft und Schriften zur Naturphilosophie. Darmstadt: Wissenschaftliche Buchgesellschaft, 1983, p. 233-620.

KORSCH, Dietrich. Das doppelte Absolute. Der Geist als Medium von Reflexion und Religion. In: Dialektische Theologie nach Karl Barth. Tübingen: J. C. B. Mohr (Paul Siebeck), 1996, p. 241-272.

KROIS, John Michael. Problematik, Eigenart und Aktualität der Cassirerschen Philosophie der symbolischen Formen. In: BRAUN, Hans-Jürg; HOLZHEY, Helmut; ORTH, Ernst Wolfgang. (Hg.). Über Ernst Cassirers Philosophie der symbolischen Formen. Frankfurt am Main: Suhrkamp Verlag, 1988, p. 15-44.

KRÜGER, Gerhard. Philosophie und Moral in der kantischen Kritik. Tübingen: J. C. B. Mohr (Paul Siebeck), 1967.

LOOF, Hans. Der Symbolbegriff in der neuren Religionsphilosophie und Theologie. Kantstudien: Ergänzungsheft 69. Köln: Kölner Universität-Verlag, 1955.

MALY, Sebastian. Kant über die symbolische Erkenntnis Gottes. Berlin; Boston: Walter de Gruyter GmbH \& Co. KG, 2012.

MEYER-BLANCK, Michael. Ernst Cassirers Symbolbegriff - zeichentheoretisch gegengelesen. In: KORSCH, Dietrich; RUDOLPH, Enno. (Hg.). Die Prägnanz der Religion in der Kultur: Ernst Cassirer und die Theologie. Tübingen: J. C. B. Mohr (Paul Siebeck), 2000, p. 91-99.

MÜLLER, Wolfgang W. Das Symbol in der dogmatische Theologie: eine symboltheologische Studie anhand der Theorien bei K. Rahner, P. Tillich, P. Ricoeur und J. Lacan. Frankfurt am Main; Bern; New York; Paris: Peter Lang $\mathrm{GmbH}$; Internationaler Verlag der Wissenschaften, 1990. 
NEUGEBAUER, Georg. Die geistphilosophischen Grundlagen der Kulturtheologie Tillichs vor dem Hintergrund seiner Schelling- und Husserlrezeption. In: DANZ, Christian; SCHÜßLER, Werner. (Hg.). Paul Tillichs Theologie der Kultur: Aspekte, Probleme, Perspektiven. Berlin; Boston: Walter de Gruyter GmbH \& Co. KG, 2011, p. 38-63.

NÖRENBERG, Klaus-Dieter. Analogia Imaginis. Der Symbolbegriff in der Theologie Paul Tillichs. Gütersloh: Gütersloher Verlagshaus Gerd Mohn, 1966.

PALMER, Michael. Paul Tillich's Theology of Culture. In: PALMER, Michael. (Hg.). Main Works - Hauptwerke. Band 2: Kulturphilosophische Schriften. Berlin; New York: Walter de Gruyter; Evangelisches Verlagswerk, 1990, p. $1-31$.

PIEPER, Annemarie. Kant und die Methode der Analogie. In: SCHÖNRICH, Gerhard; KATO, Yasushi. (Hg.). Kant in der Discussion der Moderne. Frankfurt am Main: Suhrkamp Verlag, p. 92-112.

RECKI, Birgit. Die Dialektik der ästhetischen Urteilskraft und die Methodenlehre des Geschmacks ( $§ 55-60$ ). In: HÖFFE, Otfried. (Hg.). Kritik der Urteilskraft. Berlin: Akademie Verlag GmbH, 2008, p. 189-210.

REPP, Martin. Die Transzendierung des Theismus in der Religionsphilosophie Paul Tillichs. Frankfurt am Main; Bern; New York: Peter Lang, 1986.

RINGLEBEN, Joachim. Symbol und göttliches Sein. In: HUMMEL, Gert. (Ed.). God and Being: The Problem of Ontology in the Philosophical Theology of Paul Tillich. Contributions made to the II. International Paul Tillich Symposium held in Frankfurt 1988. Berlin; New York: Walter de Gruyter \& Co., 1989, p. 165-181.

SCHARF, Uwe Carsten. The Concept of the Breakthrough of Revelation in Tillich's Dogmatik of 1925. In: PARRELLA, Frederick J. (Ed.). Paul Tillich's Theological Legacy: Spirit and Community. International Paul Tillich Conference, New Harmony, 17-20 June 1993. Berlin; New York: Walter de Gruyter \& Co., 1995, p. 65-81.

SCHÖNRICH, Gerhard. Kategorien und transzendentale Argumentation. Kant und die Idee einer transzendentalen Semiotik. Frankfurt am Main: Suhrkamp Verlag, 1981.

SCHÜßLER, Werner. Der philosophische Gottesgedanke im Frühwerk Paul Tillichs (1910 - 1933). Darstellung und Interpretation seiner Gedanken und Quellen. Würzburg: Königshausen \& Neumann, 1986.

. Paul Tillich und Karl Barth. Ihre erste Begegnung in den zwanziger Jahren. In: „Was uns unbedingt angeht". Studien zur Theologie und Philosophie Paul Tillichs. Berlin; Münster: LIT Verlag, 2009, p. 119-129. 
ULRICH, Thomas. Ontologie, Theologie, gesellschaftliche Praxis. Studien zum religiösen Sozialismus Paul Tillichs und Carl Mennickes. Zürich: Theologischer Verlag, 1971.

WAGNER, Falk. Absolute Positivität. Das Grundthema der Theologie Paul Tillichs. Neue Zeitschrift für Systematische Theologie und Religionsphilosophie, 15, p. 172-191, 1973.

WENZ, Gunther. Subjekt und Sein. Die Entwicklung der Theologie Paul Tillichs. München: Christian Kaiser Verlag, 1979.

WITTEKIND, Folkart. Grund- und Heilsoffenbarung. Zur Ausformung der Christologie Tillichs in der Auseinandersetzung mit Karl Barth. In: DANZ, Christian; SCHÜßLER, Werner; STURM, Erdmann. (Hg.). Internationales Jahrbuch für die Tillich-Forschung. Band 6: Jesus of Nazareth and the New Being in History. Berlin; Boston: Walter de Gruyter GmbH, 2013, p. 89-119. ZIJDERVELD, Anton C. Rickert's Relevance: The Ontological Nature and Epistemological Functions of Values. Leiden; Boston: Koninklijke Brill NV, 2006. 